\title{
High throughput sequencing and RT-qPCR assay reveal the presence of rose cryptic virus-1 in the United Kingdom
}

\author{
Ines Vazquez-Iglesias ${ }^{1,2} \cdot$ Ian Patrick Adams ${ }^{1,2}$. Jennifer Hodgetts ${ }^{1,3}$. Aimee Fowkes ${ }^{1} \cdot$ Stephen Forde ${ }^{1}$. \\ Richard Ward ${ }^{1}$. Adam Buxton-Kirk ${ }^{1}$. Michael Kelly ${ }^{1}$. Jone Santin-Azcona ${ }^{1,2}$ • Anna Skelton ${ }^{1} \cdot$ Valerie Harju ${ }^{1}$. \\ Neil Boonham ${ }^{2} \cdot$ Rebekah Robinson ${ }^{4} \cdot$ Gerard Clover $^{4} \cdot$ Adrian Fox $^{1}$
}

Received: 8 November 2018 / Accepted: 6 April 2019/Published online: 6 May 2019

(C) The Author(s) 2019

\begin{abstract}
Rose cryptic virus-1 (RoCV1) also known as Rosa multiflora cryptic virus is a partitivirus affecting roses, one of the most important ornamental crops worldwide. RoCV1 has previously been reported in the US, Canada and New Zealand, and has now been identified in the United Kingdom for the first time. Using High Throughput Sequencing (HTS) RoCV1 sequences were found in two samples collected in 2007 and 2012. This discovery led to the development of a RT-qPCR (TaqMan) assay for the detection of this virus. As part of a rose virus survey in the UK, 251 samples were analysed using the newly developed RoCV1 RT-qPCR test, following ELISA analysis for other common rose viruses. The results of the RT-qPCR test were confirmed using published conventional PCR primers and Sanger sequencing of amplified products. Results suggest that RoCV1 could have been infecting roses in the UK since at least 2007, with a large number of recently collected samples (43\%) found to be infected. Cryptoviruses are not thought to cause direct economic losses in their plant host, although it is not clear what impact they might have in mixed infections.
\end{abstract}

Keywords RoCV1 $\cdot$ TaqMan $\cdot$ HTS $\cdot$ Rosa $\cdot$ Diagnostic methods

Roses are one of the most important ornamental crops worldwide, they are grown for their desirable aesthetics and scent for gardens and landscaping, and their use in industrial products (Dobhal et al. 2016). The garden industry contributes $£ 9$ billion to the UK economy every year. The UK's Department for Environment, Food \& Rural Affairs (Defra) valued ornamental plant production at $£ 1.1$ billion in 2015 , with an estimated

Electronic supplementary material The online version of this article (https://doi.org/10.1007/s42161-019-00307-5) contains supplementary material, which is available to authorized users.

Ines Vazquez-Iglesias

Ines.Vazquez@fera.co.uk

1 Fera Science Ltd., The National Agri-Food Innovation Campus, Sand Hutton, York YO41 1LZ, UK

2 School of Natural and Environmental Sciences, Agriculture Building, King's Road, Newcastle upon Tyne NE1 7RU, UK

3 Present address: Elsoms Seeds Ltd., Pinchbeck Road, Spalding, Lincolnshire PE11 1QG, UK

4 The Royal Horticultural Society, Wisley, Woking, Surrey GU23 6QB, UK disease loss of $£ 630$ million within UK ornamental plant production of which $£ 40$ million could be attributed specifically to viral diseases (Department for Environment 2016; Little 2016).

A number of viruses have been reported affecting roses in the UK including arabis mosaic virus (ArMV), prunus necrotic ringspot virus (PNRSV) and strawberry latent ringspot virus (SLRSV) (Thomas 1984). Rose mosaic disease, one of the most common diseases in roses, is caused by single or mixed infections of these viruses, and others such as apple mosaic virus (ApMV). Symptoms include chlorotic line patterns, ring spots, mottles in leaves, yellow net and yellow mosaic. Infected plants are less vigorous and more likely to die during winter (Horst et al. 1983).

Rose cryptic virus-1 (RoCV1) also known as Rosa multiflora cryptic virus (Martin and Tzanetakis 2008) is a partitivirus, related to other species in the genus Alphacryptovirus, but not yet classified within this genus (King et al. 2012).

Partitivirus genomes are generally composed of two monocistronic dsRNA segments of 1.4-3.0 kbp, which are encapsidated in isometric particles about $30-40 \mathrm{~nm}$ in diameter. The larger RNA encodes a viral RNA-dependent RNA polymerase (RdRp), and the smaller one encodes a coat 
protein (CP) (King et al. 2012). However, RoCV1 has been shown to contain a third dsRNA segment (Sabanadzovic and Abou Ghanem-Sabanadzovic 2008), the origin of which is not clear, though several hypotheses have been published: (i) it may represent a co-infection by two different partitiviruses, (ii) the virus may possess two different versions of dsRNA2, or (iii) the third dsRNA element may represent a satellite virus (Nibert et al. 2014).

Cryptoviruses are reported to be widespread in nature and have escaped detection for many years because most of them cause no visible symptoms or, in a few situations, very mild symptoms (Hull 2014). RoCV1 has been found in asymptomatic plants as well as plants with mottling, leaf spots and necrosis (Milleza et al. 2013), as well as in mixed infections with rose spring dwarf-associated virus (Salem et al. 2008) or rose rosette emaravirus (Martin and Tzanetakis 2008).

In common with other partitiviruses there are no known natural vectors for RoCV1, it cannot move from cell-to-cell but can be transmitted by pollen and seed (Boccardo et al. 1987).

It was first reported in the US and it is thought to be widespread there, being reported from several locations (Martin and Tzanetakis 2008; Sabanadzovic and Abou GhanemSabanadzovic 2008; Lockhart et al. 2011). Subsequently it has been reported in New Zealand, being the most prevalent virus infecting roses (Milleza et al. 2013), and in Canada (James et al. 2015). This is the first report describing the detection of RoCV1 in rose in the United Kingdom.

Rose samples were submitted to the plant clinic at Fera Science Ltd. (York, UK) in 2007 (LS11S16) and 2012 (LS13S9), suspected of having a viral infection based on symptoms: distortion on new growth, and wrinkled and streaked leaves. ELISA analysis was performed for a range of viruses using commercially available kits following the manufacturer's instructions, as follows: arabis mosaic virus (ArMV; Leibniz Institute DSMZ GmbH, Germany); prunus necrotic ringspot virus (PNRSV; Loewe Biochemica $\mathrm{GmbH}$, Germany); apple mosaic virus (ApMV; Loewe Biochemica $\mathrm{GmbH}$, Germany); strawberry latent ringspot virus (SLRSV; BIOREBA AG, Switzerland); and impatiens necrotic spot virus (INSV; BIOREBA AG, Switzerland). In each case a negative control corresponding to the same host plant species as the test sample was used. The result was considered positive when the optical density (OD) value at $405 \mathrm{~nm}$ after $1 \mathrm{~h}$ for a given sample was greater than $3 \times$ the mean OD value of the corresponding negative control. Each sample was tested in duplicate. Sample LS11S16 gave a positive result for ApMV and sample LS13S9 gave a positive result for SLRSV.

Subsequently, High Throughput Sequencing (HTS) using nucleic acid extracted from samples LS11S16 and LS13S9 was performed. Ribosome depleted indexed sequencing libraries were prepared from extracted RNA using the ScriptSeq complete plant leaf kit (Illumina, USA) which were then sequenced on an Illumina MiSeq instrument using a V3, $2 \times 300$ cycle run kit (Illumina, USA). Sequence reads were trimmed for quality using Sickle (Najoshi 2011), assembled using Trinity (Grabherr et al. 2011) and then compared to the GenBank nr and nt databases using BLAST+ (Camacho et al. 2009). Reads of viral origin were inspected using MEGAN community edition (Huson et al. 2016). Sequences of RoCV1 were detected in both samples: for LS11S16, the total number of reads was 654,746 and 1893 mapped to RoCV1 (GenBank Accession Nos. MK075821; MK075822; MK075823; MK075824; MK075825). For LS13S9, the total number of reads was 317,946 and 62 mapped to RoCV1 (MK075826; MK075827; MK075828).

As part of a survey of rose viruses in the UK, 251 leaf samples were collected in autumn 2017 and spring/early summer 2018 from roses in the Royal Horticultural Society gardens at Harlow Carr (Harrogate, North Yorkshire, UK) and Wisley (Woking, Surrey, UK). In addition, samples of rose leaves were taken from a nursery in the Midlands, a public garden near London, the Royal National Rose Society Garden (St Albans, UK) and from samples submitted to the plant clinic at Fera Science Ltd. (York, UK).

ELISA analysis was performed for the same viruses as described above, and also tested for the following: alfalfa mosaic virus (AMV; BIOREBA AG, Switzerland); raspberry ringspot virus (RpRSV; Leibniz Institute DSMZ GmbH, Germany); cucumber mosaic virus (CMV; Agdia Inc., US); tomato spotted wilt virus (TSWV; Leibniz Institute DSMZ $\mathrm{GmbH}$, Germany); and tobacco ringspot virus (TRSV; Agdia Inc., US).

ELISA results showed that six samples were infected with SLRSV (2.4\%); ten samples were infected with ArMV (4\%); and three samples with both viruses (1.2\%).

To further investigate the incidence of RoCV1 in the UK, primers and a probe for the specific detection of RoCV1 by RT-qPCR (TaqMan) were designed (RoCV1-2-Fw-5'-TGAT CGACCAAAGTTGCAACC-3'/RoCV1-2-Rv-5'-GAAG ATAAGACAATGCAGTCA CTTTCTT-3'/RoCV1-2-Pe-5'FAM-ATTCGGACTGAATTTGCTA-MGBNFQ-3') using Primer Express 3.0.1 (Applied Biosystems) in regions conserved within the RoCV1 genome (dsRNA1 segment) and divergent from other species. Sequences used for assay design included those generated using HTS, and sequences obtained from GenBank ${ }^{\circledR}$ of target and non-target viruses (NC_010346; KM598758.1; JX492318.1; EU413666.1; EU350962.1; EU024675.1; DQ093961.2).

Samples collected for the survey were analysed using the new assay. Nucleic acid was extracted from the leaf samples using a magnetic bead-based extraction method and the 
KingFisher ${ }^{\circledR} \mathrm{mL}$ platform (Thermo Scientific). Nucleic acid samples were also tested using an RT-qPCR simplex assay designed to the plant COX (Weller et al. 2000) and subsequently modified (Hughes et al. 2006). RT-qPCR was performed on previously extracted RNA in 96 well plates on either an ABI Prism 7500 or Viia7 (Applied Biosystems). Reactions contained iTaq One-step (2x), iScript ${ }^{\mathrm{TM}}$ reverse transcriptase (Bio Rad), $300 \mathrm{nM}$ of each primer (RoCV1-2Fw and RoCV1-2 Rv), $100 \mathrm{nM}$ of probe (RoCV1-2-Pe) and $1 \mu \mathrm{l}$ of extracted RNA (concentration as extracted) in a final reaction volume of $20 \mu \mathrm{l}$. The cycling conditions used were: $10 \mathrm{~min}$ at $50^{\circ} \mathrm{C}, 2 \mathrm{~min}$ at $95^{\circ} \mathrm{C}$, then 40 cycles of $15 \mathrm{~s}$ at $95^{\circ} \mathrm{C}$ and $1 \mathrm{~min}$ at $60^{\circ} \mathrm{C}$. Negative controls where water replaced template were included in all runs and all samples were tested in duplicate. Results were scored positive if a $\mathrm{C}_{\mathrm{T}}$ value $<40$ was recorded.

Previously published primers for the dsRNA2 segment (Sabanadzovic and Abou Ghanem-Sabanadzovic 2008) were used to confirm the results obtained by RT-qPCR. A two-step RT-PCR was performed on a single sample, 7B3, which tested positive for RoCV1 using RT-qPCR. Generation of cDNA was performed using SuperScript ${ }^{\mathrm{TM}}$ II Reverse Transcriptase (Thermo Scientific) following the manufacturer's instructions. cDNA ( $10 \%$ by volume) was added in a total volume of $30 \mu \mathrm{l}$, containing dNTP mix, 5x Phusion ® HF Buffer, Thermo Scientific ${ }^{\circledR}$ Phusion High-Fidelity DNA Polymerase (New England Biolabs Inc.) and primers (300 nM). Cycling was done using a C1000 ${ }^{\mathrm{TM}}$ Thermal Cycler (Bio-Rad) as follows: $30 \mathrm{~min}$ at $40^{\circ} \mathrm{C}, 5 \mathrm{~min}$ at $94^{\circ} \mathrm{C}$, followed by 40 cycles of $30 \mathrm{~s}$ at $94{ }^{\circ} \mathrm{C}, 30 \mathrm{~s}$ at $50^{\circ} \mathrm{C}$ and $45 \mathrm{~s}$ at $72{ }^{\circ} \mathrm{C}$, a final extension step of $72{ }^{\circ} \mathrm{C}$ for 10 min was included.

Using agarose gel electrophoresis, a PCR product of the expected size $(610 \mathrm{bp})$ was obtained and PCR products were purified using a QIAquick® PCR Purification Kit (Qiagen, Germany), following the manufacturer's instructions before being sequenced (Eurofins Genomics, Germany) using both PCR primers (GenBank Accession No. MK075829).

The resulting sequence was compared to published nucleic acid data (99\% identity; GenBank Accession Nos. KM598759.1; EU024677.1; EU350963.1; EU413667.1) and amino acid data (89-99\% identity; ABY60413.1; ABV89764.1; YP_001686787.1), confirming that the sample 7B3 was infected with RoCV1.

The remaining samples were then tested for RoCV1 using the RT-qPCR, the results showed $43 \%$ (75 samples of 251 , including 7B3) were positive $\left(\mathrm{C}_{\mathrm{T}}\right.$ between 17.4 and 38.4). Of these, two samples $(0.8 \%)$ were found to be co-infected with RoCV1 and SLRSV, eight (3.2\%) with RoCV1 and ArMV and two $(0.8 \%)$ with all three viruses. All the samples tested positive with the plant $\mathrm{COX}$ assay previously, confirming the success of the nucleic acid extraction.
Following conventional PCR, products from three RoCV1 positive samples $(4 \mathrm{~B} 3,13 \mathrm{~A} 3,16 \mathrm{~B} 1)$ were sent for Sanger sequencing (GenBank Accession No. MK075830; MK075831; MK075832). Comparison of the nucleic acid sequences with published data confirmed the presence of RoCV1 with a $95 \%-100 \%$ identity.

Furthermore, eight samples (11C, 16A1, 19A3, 21A1, 69A2, 74A2, 89 and 99) with high Ct values for RT-qPCR were analysed by conventional PCR. For three of these samples PCR gave a band of the expected size $(610 \mathrm{bp})$ while the remaining gave negative results. To investigate if these samples were false-positive results following RT-qPCR or false negatives following testing using conventional PCR, the DNA amplified using the RT-qPCR from the eight samples were cloned using a pGEM ${ }^{\circledR}-\mathrm{T}$ Easy Vector System (Promega), following the manufacturer's recommended protocols. Ligation of the insert was performed, bacterial cultures grown overnight after transformation, clones containing inserts were identified, and plasmid DNA was purified. Following sequencing of the plasmid inserts, comparisons were made with published sequence for RoCV1. The results showed that the sequence of all inserts have a high sequence identity (80-100\%) to GenBank accessions KM598758.1; JX492318.1; EU413666.1; EU024675.1; AFQ36917.1; YP_001686786.1 and ABV89762.1. The results led us to conclude that the samples were infected, giving positive results with the RT-qPCR and negative results with the conventional RT-PCR most likely due to lower sensitivity.

ELISA analysis of the samples in the UK rose survey demonstrated the presence of SLRSV and ArMV, both previously described in the UK (Thomas 1980). Whilst the symptoms were frequently as described in the literature, SLRSVinfected plants (Fig. 1a) and plants with mixed infections (SLRSV + ArMV) display a chlorotic mosaic whilst ArMVinfected plants have yellow vein clearing symptoms (Fig. 1b). Nevertheless, not all the samples followed this pattern, some samples infected with ArMV had chlorotic mosaic symptoms typical of SLRSV infections. Further analysis is required to confirm these results.

Based on the provenance of samples, these results suggest that RoCV1 has been in the UK at least since 2007. Following the genus demarcation criteria from the International Committee on Taxonomy of Viruses (Vainio et al. 2018), < $24 \%$ amino acid sequence identity within the RdRP gene indicates a new species. Analysis of the sequence of samples LS11S16 and LS13S9, show that the amino acid sequences for RNA1 (RdRP protein) share between $98.85-100 \%$ identity with published sequences.

RoCV1 coat protein nucleic acid sequences (dsRNA2) from this work (GenBank Accession No. MK075822; MK075824; MK075827; MK075829; MK075830; 
Fig. 1 Rose leaves showing rose mosaic disease symptoms, infected with (a) SLRSV and RoCV1 (b) ArMV and RoCV1 and (c) an asymptomatic rose stem infected with RoCV1

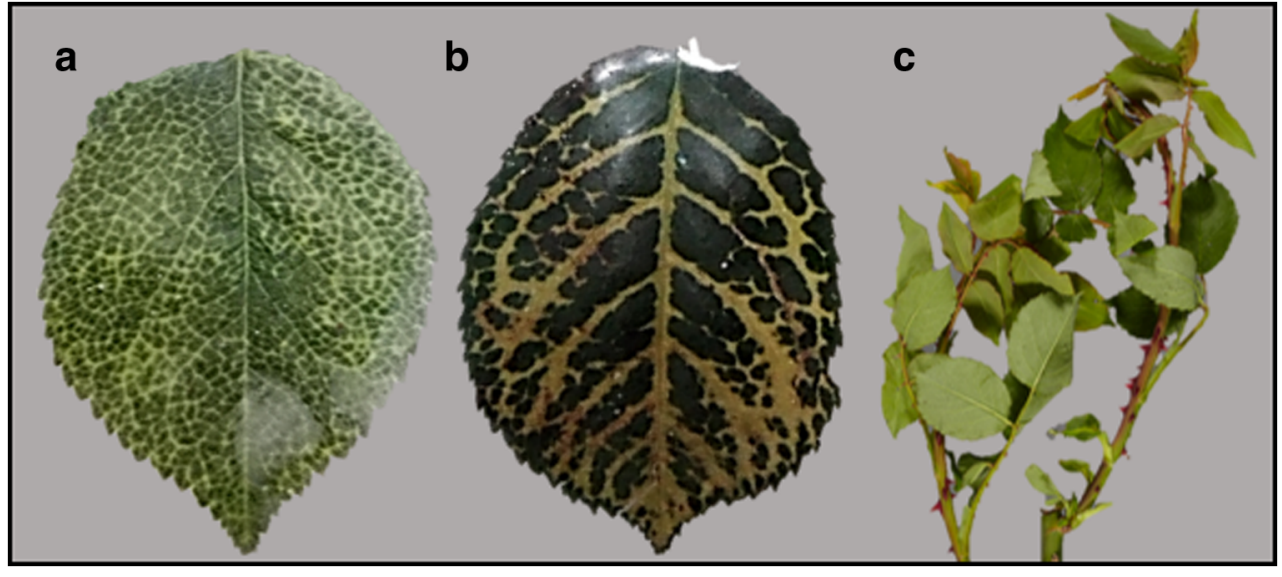

MK075831; MK075832) showed little difference $(<0.5 \%)$ between isolates. For samples LS11S16 and LS13S9 dsRNA 3 was detected (MK075823; MK075825; MK075828). Comparison of the nucleic acid sequence showed a $99 \%$ of identity with published sequences.

RoCV1 has been reported in the US (Martin and Tzanetakis 2008; Sabanadzovic and Abou GhanemSabanadzovic 2008; Lockhart et al. 2011), Canada (James et al. 2015), and New Zealand where it was the most prevalent virus in roses with a 48\% incidence (Milleza et al. 2013). By using HTS we have shown the presence of RoCV1 in the UK for the first time, follow on testing using RT-qPCR (TaqMan) has shown that a large percentage (43\%) of the samples tested were infected with RoCV1. There is no known natural vector for RoCV1; it is assumed to be pollen and seed transmitted like other cryptoviruses. Therefore, it is probable that RoCV1 has spread between the US, New Zealand, Canada and the UK during commercial trade of planting material.

In New Zealand, infected roses were associated with mottling, leaf spots and necrosis and also one with flower break but it was also found in asymptomatic samples (Milleza et al. 2013). In this study, several samples were asymptomatic, others had vein banding, mottling or leaf distortion symptoms. It is possible that these symptoms could be caused by another, as yet unidentified virus (or pathogen), by herbicide damage or adverse cultural conditions.

A sample with symptoms similar to those caused by rose rosette virus was positive for RoCV1; further studies will be undertaken to investigate if those symptoms were due to mixed infections with other, as yet undescribed viruses. We also found roses with symptoms of rose mosaic disease which were infected with RoCV1, where ELISA analysis indicated that they were co-infected with ArMV, SLRSV or all three viruses. It is unknown whether the symptoms caused by ArMV or SLRSV were impacted by co-infection with RoCV1, although we found samples with mosaic symptoms which were not infected with RoCV1. Cryptoviruses are not thought to cause direct economic losses in their plant host, although it is not clear what impact they have in mixed infections.

Acknowledgements This work was carried out as part of a joint studentship funded by the Fera Science Ltd.- Department for Environment, Food and Rural Affairs (DEFRA) long-term service agreement (LTSA), the Royal Horticultural Society, and Newcastle University.

\section{Compliance with ethical standards}

Conflict of interest The authors declare that they have no conflict of interest.

Ethical approval This article does not contain any studies with human participants or animals performed by any of the authors. It is original and has not been submitted or published elsewhere.

Informed consent Informed consent was obtained from all individual participants included in the study. All the authors have seen and approved the manuscript, and all have taken a valid role through either study design, data generation or manuscript preparation.

Open Access This article is distributed under the terms of the Creative Commons Attribution 4.0 International License (http:// creativecommons.org/licenses/by/4.0/), which permits unrestricted use, distribution, and reproduction in any medium, provided you give appropriate credit to the original author(s) and the source, provide a link to the Creative Commons license, and indicate if changes were made.

\section{References}

Boccardo G, Lisa V, Luisoni E, Milne R (1987) Cryptic plant viruses. Adv Virus Res 32:171-214. https://doi.org/10.1016/S00653527(08)60477-7

Camacho C, Coulouris G, Avagyan V, Ma N, Papadopoulos J, Bealer K, Madden TL (2009) BLAST+: architecture and applications. BMC Bioinformatics 10:421-421. https://doi.org/10.1186/1471-2105-10421

Department for Environment, Food and Rural Affairs (2016) Agriculture in the United Kingdom 2015 National Statistics. https://www.gov. uk/government/statistics/agriculture-in-the-united-kingdom-2015 . Accessed 9 Oct 2017 
Dobhal S, Olson JD, Arif M, Garcia Suarez JA, Ochoa-Corona FM (2016) A simplified strategy for sensitive detection of Rose rosette virus compatible with three RT-PCR chemistries. J Virol Methods 232:47-56. https://doi.org/10.1016/j.jviromet.2016.01.013

Grabherr MG et al (2011) Full-length transcriptome assembly from RNASeq data without a reference genome. Nat Biotechnol 29:644. https://doi.org/10.1038/nbt.1883

Horst RK, Society AP, University C (1983) Compendium of rose diseases American Phytopathological Society in cooperation with Dept. of Plant Pathology, Cornell University, St. Paul, USA.

Hughes K, Tomlinson J, Griffin R, Boonham N, Inman A, Lane C (2006) Development of a one-step real-time polymerase chain reaction assay for diagnosis of Phytophthora ramorum. Phytopathology 96: 975-981. https://doi.org/10.1094/PHYTO-96-0975

Hull R (2014) Plant Virology, 5th edn. Elsevier, John Innes Centre, Norwich. https://doi.org/10.1016/B978-0-12-384,871-0.00019-4

Huson DH et al (2016) MEGAN Community Edition - Interactive Exploration and Analysis of Large-Scale Microbiome Sequencing Data. PLoS Comput Biol 12:e1004957. https://doi.org/10.1371/ journal.pcbi.1004957

James D, Phelan J, Varga A, Rott M (2015) First report of Rose cryptic virus 1 in Rosa plants in Canada. Plant Dis 99:558. https://doi.org/ 10.1094/PDIS-09-14-0921-PDN

King A, Lefkowitz E, Admas M, Carstens E (2012) Ninth Report of the International Committee on Taxonomy of Viruses. Elsevier.

Little EL (2016) UGA Extension AP 102-7, Georgia Plant Disease Loss Estimates 2014. http://extension.uga.edu/publications/detail.html? number=AP102-7\&title $=2014 \% 20$ Georgia $\% 20$ Plant $\% 20$ Disease $\%$ 20Loss\%20Estimates . Accessed 14 Nov 2017

Lockhart B, Zlesak D, Fetzer J (2011) Identification and partial characterization of six new viruses of cultivated roses in the USA. Acta Hortic 901:139-148. https://doi.org/10.17660/ActaHortic.2011. 901.18

Martin RR, Tzanetakis IE (2008) First Report of Rosa multiflora cryptic virus in Rosa multiflora in the Eastern United States. Plant Dis 92: 1706. https://doi.org/10.1094/PDIS-92-12-1706B
Milleza EJM, Ward LI, Delmiglio C, Tang JZ, Veerakone S, PerezEgusquiza Z (2013) A survey of viruses infecting Rosa spp. in New Zealand. Australas Plant Pathol 42:313-320. https://doi.org/ 10.1007/s13313-012-0191-x

Najoshi (2011) Sickle- A windowed adaptive trimming tool for FastQ files using quality. https://github.com/najoshi/sickle . Accessed 11 Jan 2016

Nibert ML, Ghabrial SA, Maiss E, Lesker T, Vainio EJ, Jiang D, Suzuki N (2014) Taxonomic reorganization of family Partitiviridae and other recent progress in partitivirus research. Virus Res 188:128-141. https://doi.org/10.1016/j.virusres.2014.04.007

Sabanadzovic S, Abou Ghanem-Sabanadzovic N (2008) Molecular characterization and detection of a tripartite cryptic virus from rose. J Plant Pathol 90:287-293. https://doi.org/10.4454/jpp.v90i2.664

Salem NM, Golino DA, Falk BW, Rowhani A (2008) Complete nucleotide sequences and genome characterization of a novel doublestranded RNA virus infecting Rosa multiflora. Arch Virol 153:455. https://doi.org/10.1007/s00705-007-0008-3

Thomas BJ (1980) The detection by serological methods of viruses infecting the rose. Ann Appl Biol 94:91-101. https://doi.org/10.1111/ j.1744-7348.1980.tb03900.x

Thomas BJ (1984) Studies on Rose Mosaic Disease in field-grown roses produced in the United Kingdom. Ann Appl Biol 98:419-429. https://doi.org/10.1111/j.1744-7348.1981.tb00774.x

Vainio E et al (2018) ICTV Virus Taxonomy Profile: Partitiviridae. J Gen Virol 99:17-18. https://doi.org/10.1099/jgv.0.000985

Weller SA, Elphinstone JG, Smith NC, Boonham N, Stead DE (2000) Detection of Ralstonia solanacearum strains with a quantitative, multiplex, real-time, fluorogenic PCR (TaqMan) assay. Appl Environ Microbiol 66:2853-2858

Publisher's note Springer Nature remains neutral with regard to jurisdictional claims in published maps and institutional affiliations. 